\title{
The Cyclic AMP Pathway
}

\section{Paolo Sassone-Corsi}

Center for Epigenetics and Metabolism, School of Medicine, University of California, Irvine, California 92697

Correspondence:psc@uci.edu

Cyclic adenosine $3^{\prime}, 5^{\prime}$-monophosphate (cAMP) was the first second messenger to be identified and plays fundamental roles in cellular responses to many hormones and neurotransmitters (Sutherland and Rall 1958). The intra- cellular levels of cAMP are regulated by the balance between the activities of two enzymes (see Fig. 1): adenylyl cyclase (AC) and cyclic nucleotide phosphodiesterase (PDE). Different isoforms of these enzymes are encoded by a large

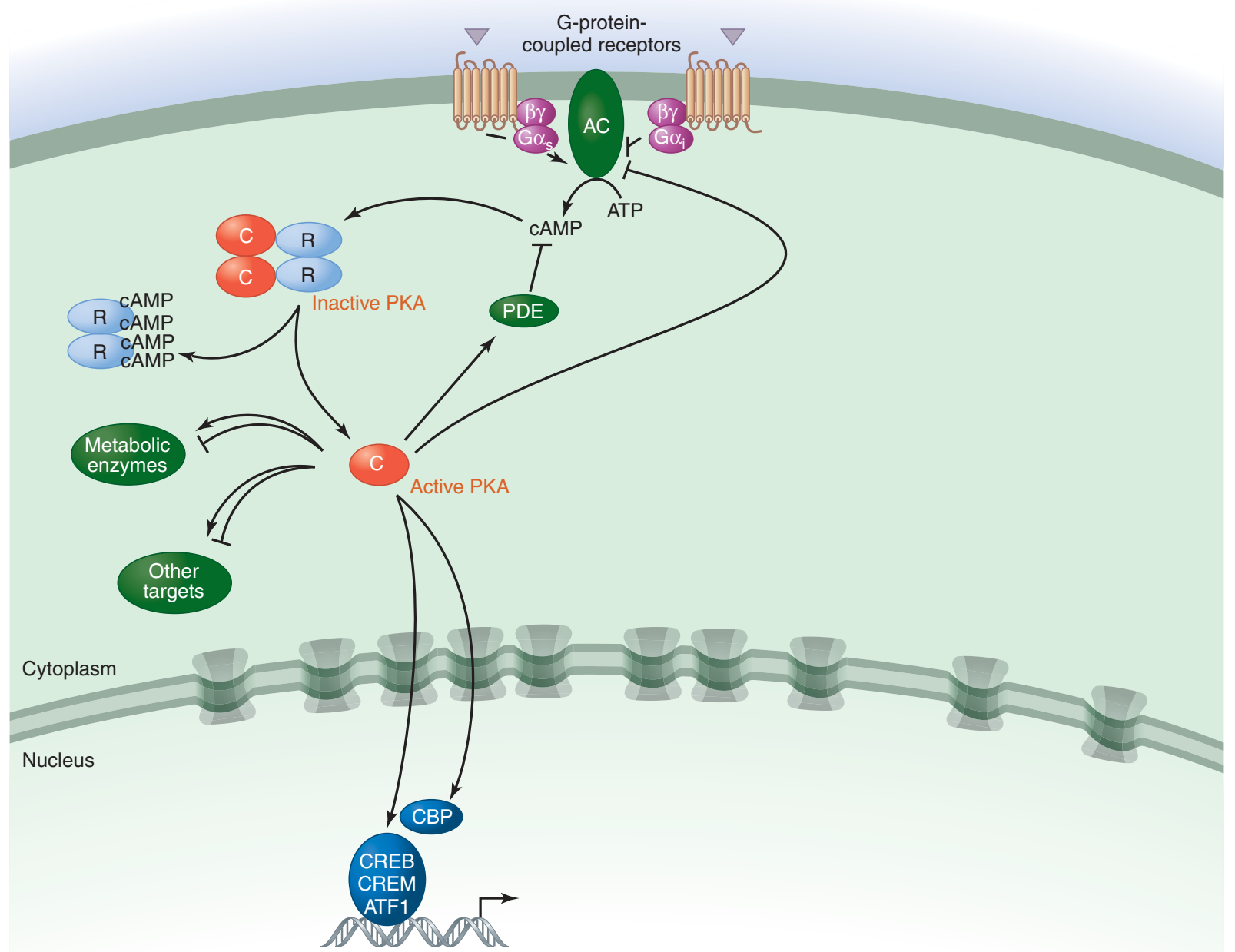

Figure 1. PKA regulation. 
number of genes, which differ in their expression patterns and mechanisms of regulation, generating cell-type and stimulus-specific responses (McKnight 1991).

Most ACs (soluble bicarbonate-regulated ACs are the exception) are activated downstream from G-protein-coupled receptors (GPCRs) such as the $\beta$ adrenoceptor by interactions with the $\alpha$ subunit of the $\mathrm{G}_{\mathrm{s}}$ protein $\left(\alpha_{\mathrm{s}}\right) . \alpha_{\mathrm{s}}$ is released from heterotrimeric $\alpha \beta \gamma$ G-protein complexes following binding of agonist ligands to GPCRs (e.g., epinephrine in the case of $\beta$ adrenoceptors) and binds to and activates AC. The $\beta \gamma$ subunits can also stimulate some AC isoforms. cAMP generated as a consequence of AC activation can activate several effectors, the most well studied of which is cAMP-dependent protein kinase (PKA) (Pierce et al. 2002).

Alternatively, AC activity can be inhibited by ligands that stimulate GPCRs coupled to $\mathrm{G}_{\mathrm{i}}$ and/or cAMP can be degraded by PDEs. Indeed both ACs and PDEs are regulated positively and negatively by numerous other signaling pathways (see Fig. 2), such as calcium signaling (through calmodulin [CaM], CamKII, CamKIV, and calcineurin [also know as PP2B]), subunits of other G proteins (e.g., $\alpha_{\mathrm{i}}, \alpha_{\mathrm{o}}$, and $\alpha_{\mathrm{q}}$ proteins, and the $\beta \gamma$ subunits in some cases), inositol lipids (by PKC), and receptor tyrosine kinases (through the ERK MAP kinase and PKB) (Yoshimasa et al. 1987; Bruce et al. 2003; Goraya and Cooper 2005).

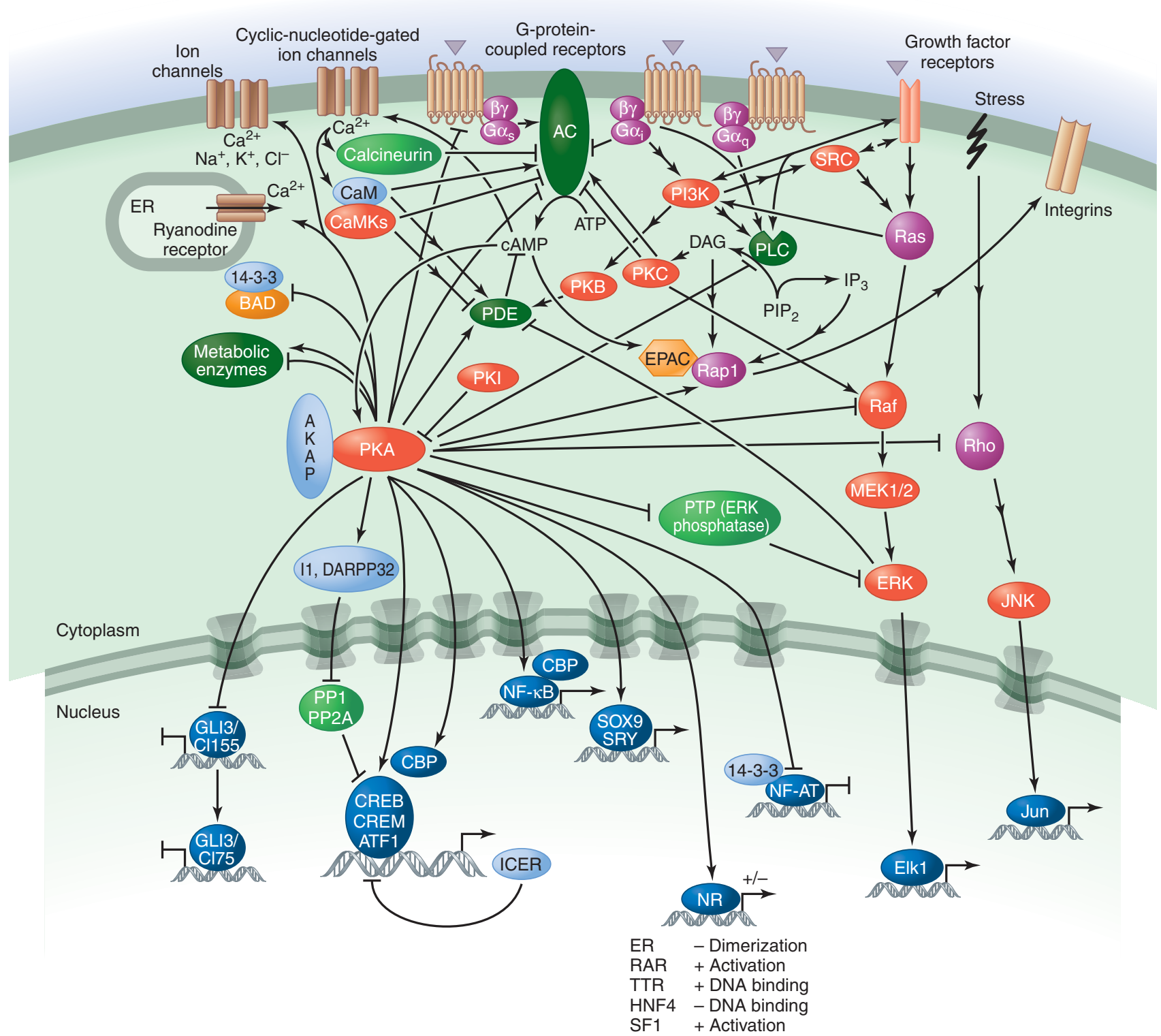

Figure 2. The cAMP/PKA pathway. 
Crosstalk with other pathways provides further modulation of the signal strength and cell-type specificity, and feedforward signaling by PKA itself stimulates PDE4.

There are three main effectors of cAMP: PKA, the guanine-nucleotide-exchange factor (GEF) EPAC and cyclicnucleotide-gated ion channels. Protein kinase (PKA), the best-understood target, is a symmetrical complex of two regulatory (R) subunits and two catalytic (C) subunits (there are several isoforms of both subunits). It is activated by the binding of cAMP to two sites on each of the $\mathrm{R}$ subunits, which causes their dissociation from the $\mathrm{C}$ subunits (Taylor et al. 1992). The catalytic activity of the C subunit is decreased by a protein kinase inhibitor (PKI), which can also act as a chaperone and promote nuclear export of the $\mathrm{C}$ subunit, thereby decreasing nuclear functions of PKA. PKA-anchoring proteins (AKAPs) provide specificity in cAMP signal transduction by placing PKA close to specific effectors and substrates. They can also target it to particular subcellular locations and anchor it to ACs (for immediate local activation of PKA) or PDEs (to create local negative feedback loops for signal termination) (Wong and Scott 2004).

A large number of cytosolic and nuclear proteins have been identified as substrates for PKA (Tasken et al. 1997). PKA phosphorylates numerous metabolic enzymes, including glycogen synthase and phosphorylase kinase, which inhibits glycogen synthesis and promotes glycogen breakdown, respectively, and acetyl CoA carboxylase, which inhibits lipid synthesis. PKA also regulates other signaling pathways. For example, it phosphorylates and thereby inactivates phospholipase C (PLC) $\beta 2$. In contrast, it activates MAP kinases; in this case, PKA promotes phosphorylation and dissociation of an inhibitory tyrosine phosphatase (PTP). PKA also decreases the activities of Raf and Rho and modulates ion channel permeability. In addition, it regulates the expression and activity of various ACs and PDEs.

Regulation of transcription by PKA is mainly achieved by direct phosphorylation of the transcription factors cAMP-response element-binding protein (CREB), cAMPresponsive modulator (CREM), and ATF1. Phosphorylation is a crucial event because it allows these proteins to interact with the transcriptional coactivators CREBbinding protein (CBP) and p300 when bound to cAMPresponse elements (CREs) in target genes (Mayr and Montminy 2001). The CREM gene also encodes the powerful repressor ICER, which negatively feeds back on cAMP-induced transcription (Sassone-Corsi 1995). Note, however, that the picture is more complex, because CREB, CREM, and ATF1 can all be phosphorylated by many different kinases, and PKA can also influence the activity of other transcription factors, including some nuclear receptors.
In addition to the negative regulation by signals that inhibit AC or stimulate PDE activity, the action of PKA is counterbalanced by specific protein phosphatases, including PP1 and PP2A. PKA in turn can negatively regulate phosphatase activity by phosphorylating and activating specific PP1 inhibitors, such as I1 and DARPP32. PKApromoted phosphorylation can also increase the activity of PP2A as part of a negative feedback mechanism.

Another important effector for cAMP is EPAC, a GEF that promotes activation of certain small GTPases (e.g., Rap1). A major function of Rap1 is to increase cell adhesion via integrin receptors (how this occurs is unclear) (Bos 2003).

Finally, cAMP can bind to and modulate the function of a family of cyclic-nucleotide-gated ion channels. These are relatively nonselective cation channels that conduct calcium. Calcium stimulates CaM and CaM-dependent kinases and, in turn, modulates cAMP production by regulating the activity of ACs and PDEs (Zaccolo and Pozzan 2003). The channels are also permeable to sodium and potassium, which can alter the membrane potential in electrically active cells.

Figure 2 adapted from Fimia and Sassone-Corsi (2001).

\section{REFERENCES}

Bos JL. 2003. Epac: A new cAMP target and new avenues in cAMP research. Nat Rev Mol Cell Biol 4: 733-738.

Bruce JI, Straub SV, Yule DI. 2003. Crosstalk between cAMP and $\mathrm{Ca}^{2+}$ signaling in non-excitable cells. Cell Calcium 34: 431-444.

Fimia GM, Sassone-Corsi P. 2001. Cyclic AMP signaling. J Cell Sci 114: $1971-1972$

Goraya TA, Cooper DMF. 2005. $\mathrm{Ca}^{2+}$-calmodulin-dependent phosphodiesterase (PDE1): Current perspectives. Cell Signal 17: 789-797.

Mayr B, Montminy M. 2001. Transcriptional regulation by the phosphorylation-dependent factor CREB. Nat Rev Mol Cell Biol 2: 599-609.

McKnight GS. 1991. Cyclic AMP second messenger systems. Curr Opin Cell Biol 3: 213-217.

Pierce KL, Premont RT, Lefkowitz RJ. 2002. Seven-transmembrane receptors. Nat Rev Mol Cell Biol 3: 639-650.

Sassone-Corsi P. 1995. Transcription factors responsive to cAMP. Annu Rev Cell Dev Biol 11: 355-377.

Sutherland EW, Rall TW. 1958. Fractionation and characterization of a cyclic adenine ribonucleotide formed by tissue particles. J Biol Chem 232: 1077-1091.

Tasken K, Skalhegg BS, Tasken KA, Solberg R, Knutsen HK, Levy FO, Sandberg M, Orstavik S, Larsen T, Johansen AK, et al. 1997. Structure, function and regulation of human cAMP-dependent protein kinases. Adv Second Messenger Phosphoprotein Res 31: 191-203.

Taylor SS, Knighton DR, Zheng J, Ten Eyck LF, Sowadski JM. 1992. Structural framework for the protein kinase family. Аnпu Rev Cell Biol 8: $429-462$.

Wong W, Scott JD. 2004. AKAP signaling complexes: Focal points in space and time. Nat Rev Mol Cell Biol 5: 959-970.

Yoshimasa T, Sibley DR, Bouvier M, Lefkowitz RJ, Caron MG. 1987. Cross-talk between cellular signaling pathways suggested by phorbolester induced adenylate cyclase phosphorylation. Nature 327: 67-70.

Zaccolo M, Pozzan T. 2003. cAMP and $\mathrm{Ca}^{2+}$ interplay: A matter of oscillation patterns. Trends Neurosci 26: 53-55. 


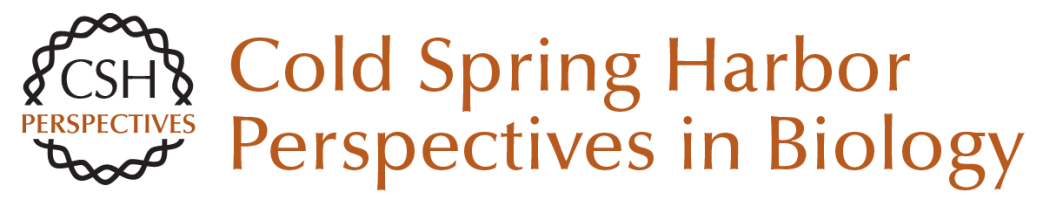

\section{The Cyclic AMP Pathway}

Paolo Sassone-Corsi

Cold Spring Harb Perspect Biol 2012; doi: 10.1101/cshperspect.a011148

Subject Collection Signal Transduction

Cell Signaling and Stress Responses Gökhan S. Hotamisligil and Roger J. Davis

Protein Regulation in Signal Transduction Michael J. Lee and Michael B. Yaffe

Synaptic Signaling in Learning and Memory Mary B. Kennedy

Vertebrate Reproduction Sally Kornbluth and Rafael Fissore

Signaling in Lymphocyte Activation Doreen Cantrell

Signaling in Muscle Contraction Ivana Y. Kuo and Barbara E. Ehrlich

Toll-Like Receptor Signaling Kian-Huat Lim and Louis M. Staudt

Signaling Pathways that Regulate Cell Division Nicholas Rhind and Paul Russell
Second Messengers

Alexandra C. Newton, Martin D. Bootman and John D. Scott

Signals and Receptors Carl-Henrik Heldin, Benson Lu, Ron Evans, et al.

Cell Death Signaling Douglas R. Green and Fabien Llambi

Signaling Networks that Regulate Cell Migration Peter Devreotes and Alan Rick Horwitz

Signaling Networks: Information Flow, Computation, and Decision Making Evren U. Azeloglu and Ravi lyengar

Signal Transduction: From the Atomic Age to the Post-Genomic Era Jeremy Thorner, Tony Hunter, Lewis C. Cantley, et al.

Signaling by the TGF $\beta$ Superfamily Jeffrey L. Wrana

Subversion of Cell Signaling by Pathogens Neal M. Alto and Kim Orth

For additional articles in this collection, see http://cshperspectives.cshlp.org/cgi/collection/

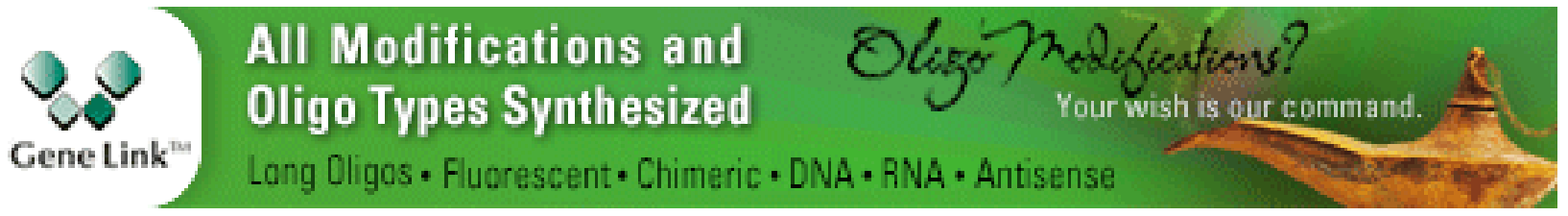

Copyright @ 2012 Cold Spring Harbor Laboratory Press; all rights reserved 